\title{
New insight into solid-state molecular dynamics: mechanochemical synthesis of azobenzene/triphenylphosphine palladacycles $\dagger$
}

\author{
Dominik Cinčić, ${ }^{a}$ Marina Juribašić, ${ }^{b}$ Darko Babić, ${ }^{b}$ Krešimir Molćanov, ${ }^{b}$ Primož Šket, ${ }^{c}$ Janez \\ Plavec and Manda Čurić* ${ }^{b}$
}

Received 29th August 2011, Accepted 8th September 2011

DOI: $10.1039 / \mathrm{c} 1 \mathrm{cc} 15377 \mathrm{c}$

\begin{abstract}
Solid-state reactions of dicyclopalladated azobenzenes and triphenylphosphine lead to the thermodynamically favorable bridged complexes. It was demonstrated for the first time that very complex molecular dynamics involving a series of structural transformations is also feasible in the solid state.
\end{abstract}

Continuous interest in the development of the mechanochemical synthetic methods has led to novel molecular and supramolecular materials. ${ }^{1}$ The main advantages of these alternative preparative routes are the absence of solvents and a reduction in environmental pollution, as well as simplicity in processing and handling. ${ }^{2}$ Furthermore, solid-state reaction s are regularly much faster, more efficient and more selective than the analogous reactions in solutions. ${ }^{3}$ Consequently, many organic, inorganic and coordination compounds have been prepared by solid-state reactions. ${ }^{4}$ In this regard, particularly interesting are dicyclopalladated azobenzenes bearing two highly labile ligands (1-4, Scheme 1) which can be easily displaced via ligand substitution. ${ }^{5}$ The presence of such ligands and their position in the crystal lattice (Fig. S1, ESI

$\dagger$ ) make dicyclopalladated azobenzenes ideal building blocks for mechanochemical synthesis of new species ranging from coordination compounds to organometallic coordination polymers or aggregates. These products, due to their structural and photophysical properties, can have broad application in organic synthesis, catalysis and design of differential chromogenic and fluorescent chemosensors. ${ }^{6}$ Derivatives of dicyclopalladated azobenzenes suitable for different purposes may be designed by appropriate selection of azobenzene ligands as well as ancillary ligands.

a Department of Chemistry, Faculty of Science, University of Zagreb, Horvatovac 102a, HR-10000 Zagreb, Croatia

b Division of Physical Chemistry, Ruđer Bošković Institute, Bijenička 54, HR-10000

Zagreb, Croatia. E-mail: curic@irb.hr; Fax: +385 1-4680245; Tel: +385 1-4680097

c Slovenian NMR Centre, National Institute of Chemistry, Hajdrihova 19, SI-1000 Ljubljana, Slovenia

$\dagger$ Electronic supplementary information (ESI) available: Experimental and computational details. CCDC 831717-831720. For ESI and crystallographic data in CIF or other electronic format see DOI: $10.1039 / \mathrm{c} 1 \mathrm{cc} 15377 \mathrm{c}$ 


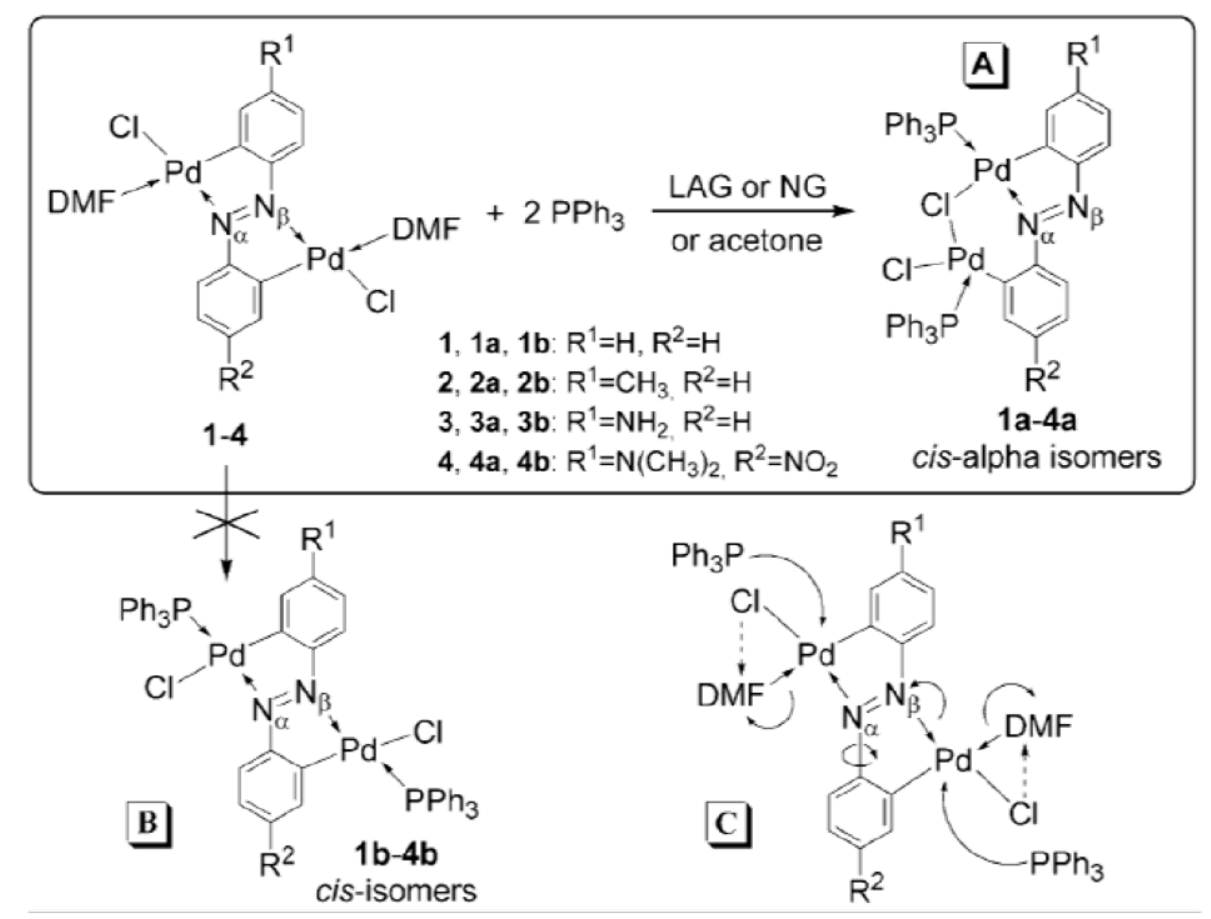

\section{Scheme 1}

Herein, we present the first example of mechanochemical synthesis of novel azobenzene/triphenylphosphine palladacycles which reveals very complex molecular dynamics induced by grinding of solid reactants, Scheme 1. We also present the structural properties of new complexes as well as the results of quantum-chemical calculations used in order to explain isomerism in isolated complexes and examine trans influence of the phosphorous and the carbon ligands.

Two types of the complexes, $\mathbf{A}$ and $\mathbf{B}$ (Scheme 1), could be obtained by reactions of complexes 1-4 and triphenylphosphine $\left(\mathrm{PPh}_{3}\right)$ in a 1:2 molar ratio. They both have one molecule of $\mathrm{PPh}_{3}$ attached to each $\mathrm{Pd}$ atom and differ in the coordination mode of azobenzenes. In A complexes, azobenzenes act simultaneously as monodentate $\mathrm{C}$ - and chelating $\mathrm{C}, \mathrm{N}$-donors as in azobenzene $/ 2,2^{0}$-bypiridine palladacycles recently reportedby us, ${ }^{6 a}$ while in $\mathbf{B}$ complexes, azobenzenes act as double chelating $\mathbf{C}, \mathrm{N}$-donors. Since two nitrogen atoms, denoted as $\mathrm{N} \alpha$ and $\mathrm{N} \beta$, in unsymmetrical substituted azobenzenes are not equivalent, two isomers (alpha and beta) of A complexes $\mathbf{2 a}-\mathbf{4 a}$ can be formed by breaking either $\mathrm{Pd}-\mathrm{N} \alpha$ or $\mathrm{Pd}-\mathrm{N} \beta$ bond. Furthermore, depending on the trans or cis orientation of phosphine ligand towards the $\mathrm{Pd}-\mathrm{C}$ bond, two isomers are possible for both types of complexes.

Liquid-assisted grinding (LAG) ${ }^{7}$ of initial compounds with two molar equivalents of $\mathrm{PPh}_{3}$ in the presence of a small quantity of nitromethane at room temperature resulted in new crystalline products $\mathbf{1 a}-\mathbf{4 a}$ as revealed by powder X-ray diffraction (PXRD), Fig.1. These 
reactions followed by a drastic colour change were complete in the range of 30-45 min depending on the initial complexes used, Fig.1 and Fig.S2 (ESI $\dagger$ ). The same products can also be prepared in the absence of solvent by neat grinding (NG) reactions but at a slower rate than in LAG reactions, confirming that a small quantity of nitromethane accelerates solid-state reactions, Fig. 2.8

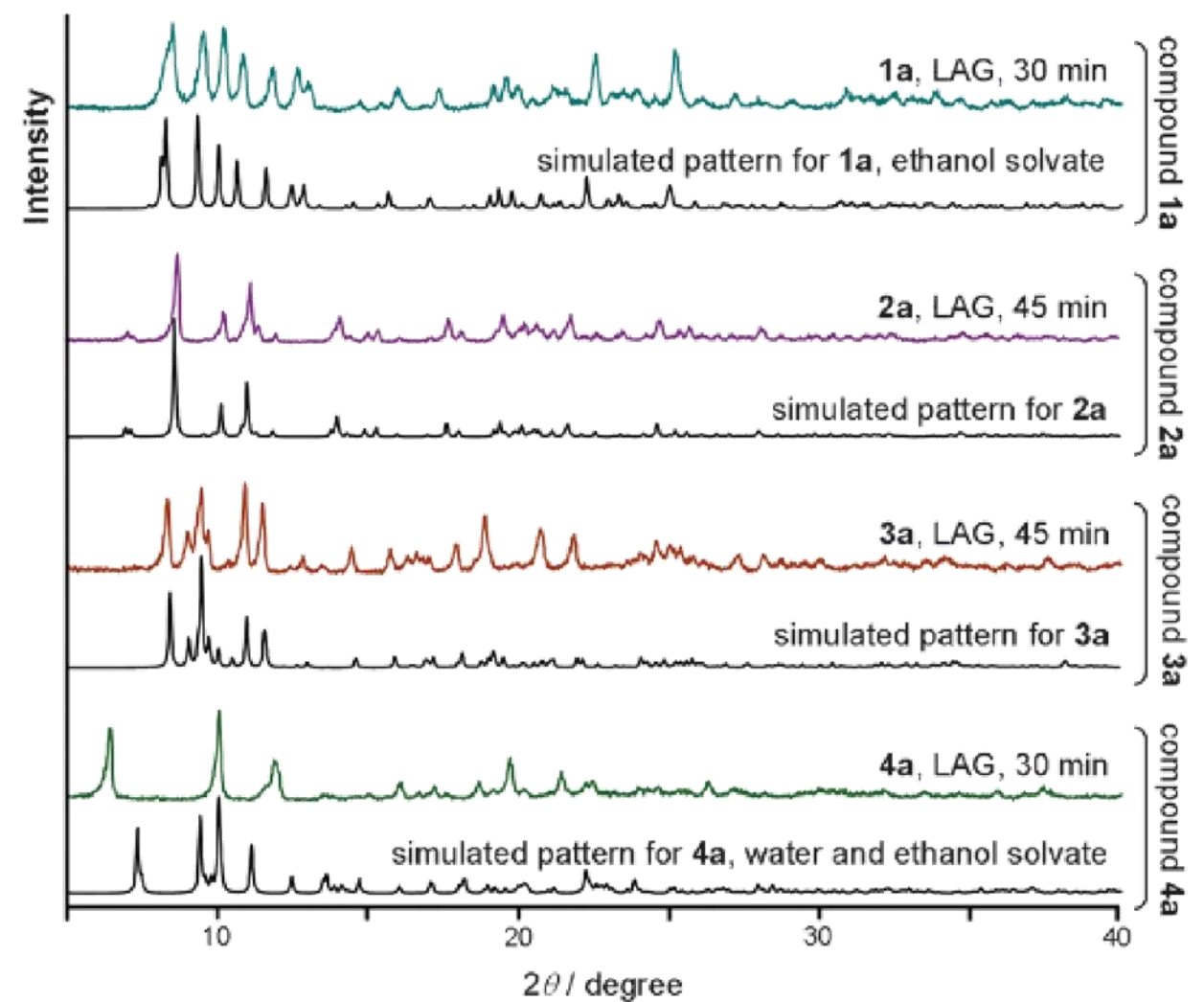

Fig 1 Comparison of PXRD patterns between products obtained by grinding and simulated from the single crystals.

Since $\mathrm{PPh}_{3}$ is a monodentate ligand it was reasonable to expect the formation of $\mathbf{B}$ complexes in the solid-state reactions of 1-4 and $\mathrm{PPh}_{3}$. However, the results of $\mathrm{X}$-ray singlecrystal and powder-diffraction experiments and solid-state ${ }^{31} \mathrm{P}$ NMR spectra, supported by quantum-chemical calculations, have confirmed that these reactions lead to the bridged complexes 1a-4a. Attempts to isolate complexes $\mathbf{1 b}-\mathbf{4 b}$ resulted in the products $1 \mathbf{a}-\mathbf{4 a}$.

Formation of bridged complexes under mechanochemical conditions is surprising since it requires very complex changes in the molecular structure during the reaction. These changes comprise substitution of DMF with $\mathrm{PPh}_{3}$,cis-trans isomerization, breaking of one $\mathrm{Pd}-\mathrm{N}$ bond, rotation of the phenyl ring with a bulky substituent and positioning of both palladium atoms on the same side of azobenzene and finally the formation of the monochloride bridge, sketch $\mathbf{C}$ in Scheme 1. The step-by-step mechanism of these transformations is not fully verified, as is 
usually the case for mechanochemical reactions. ${ }^{9}$ However, IR spectra confirmed that initial complexes do not spontaneously lose DMF upon grinding (Fig. S3, ESI $\dagger$ ) and the introduction of $\mathrm{PPh}_{3}$ should be the first step in the reaction. Besides, it is obvious that the step involving cistrans isomerization at the $\mathrm{Pd}-\mathrm{N \alpha}$ bond is prerequisite for the formation of Cl-bridge which also looks energetically more demanding than cis-trans isomerization.

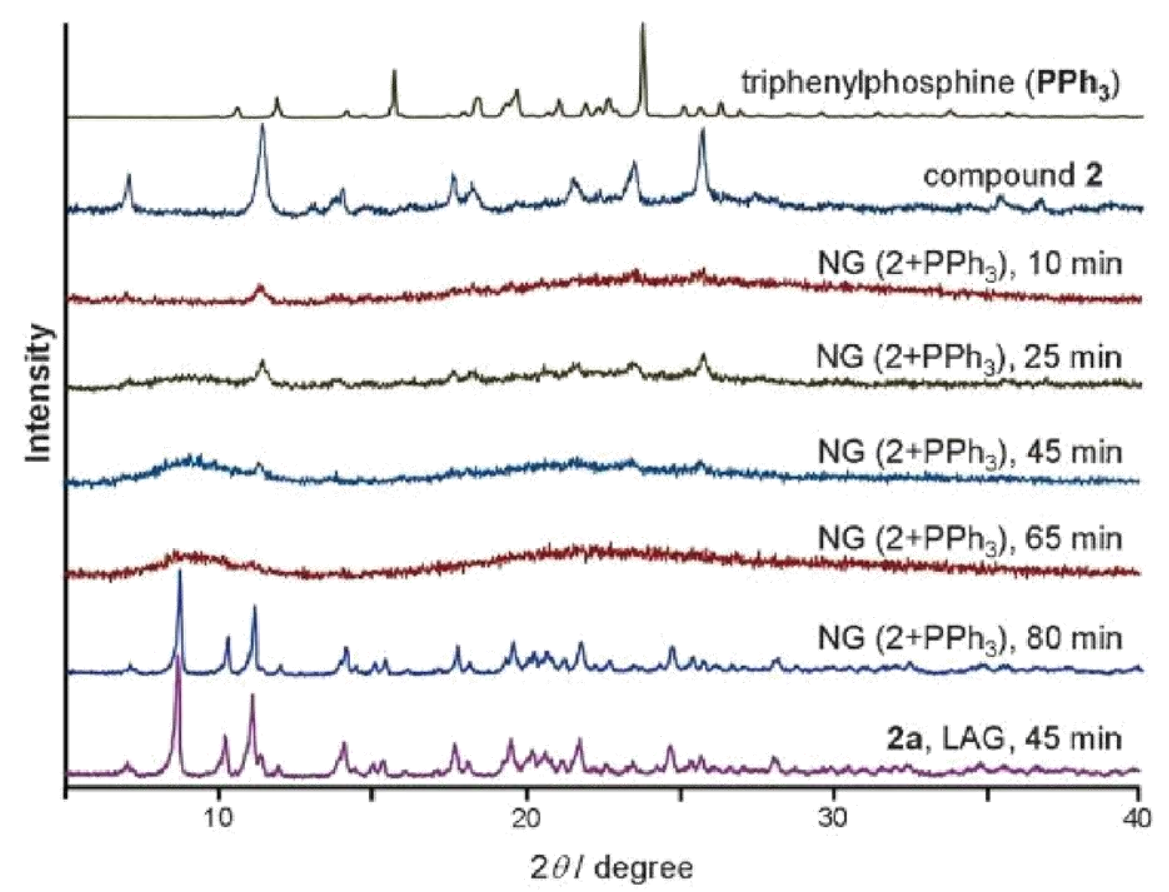

Fig 2 PXRD patterns of NG reaction of complex 2 and $\mathrm{PPh}_{3}$

The products formation in the NG reactions was qualitatively monitored by the PXRD. Fig. 2 shows that the reactants lost their crystallinity and produced amorphous material followed by the crystalline product formation. These results suggest a process that involves fast molecular diffusion with crystal disintegration and phase transformation which lead to products. Furthermore, the PXRD experiments and the solid-state ${ }^{31} \mathrm{P}$ NMR spectra confirmed that after 20 min of grinding, the reaction continued in the jar even without further mechanical treatment, and that after 24 hours the same products were formed and only a small amount of impurities was present. This is in agreement with the studies on chemical and mechanical aspects of mechanochemical synthesis. 10

In order to identify the ground species their single crystals were isolated from acetone or acetone-ethanol mixture by recrystallization, and analogous solvent-based reactions were carried out in acetone, see ESI. $\uparrow$

Results of the single crystal X-ray analysis have clearly demonstrated that crystallization of LAG species from acetone or mixture of acetone and ethanol leads to A complexes, Fig. 3 and Fig. S4-S7 (ESI $\dagger$ ). In all complexes two Pd atoms are connected by a Cl-bridge and an azobenzene ligand. Single crystals of alpha isomers were isolated for $\mathbf{3 a}$ and $\mathbf{4 a}$, while beta 
Cinčić, D., Juribašić, M.,Babić, D.,Molćanov K., Šket, P., Plavec, J. and Čurić, M. (2011), "New insight into solid state molecular dynamics: mechanochemical synthesis of azobenzene/triphenylphosphine palladacycles", Chemical Communications, Vol. 47, No. 41, pp.11543-11545.

isomer was isolated only for 2a, Fig.3 and Fig.S6 and S7 (ESI †). Furthermore, in isolated complexes phosphine ligands are cis oriented with respect to the $\mathrm{Pd}-\mathrm{C}$ bond. Formation of trans isomers is not preferred due to the destabilizing effect of carbon and phosphorus ligands in trans positions, ${ }^{11}$ as we have also confirmed by quantum-chemical calculations, Table 1.

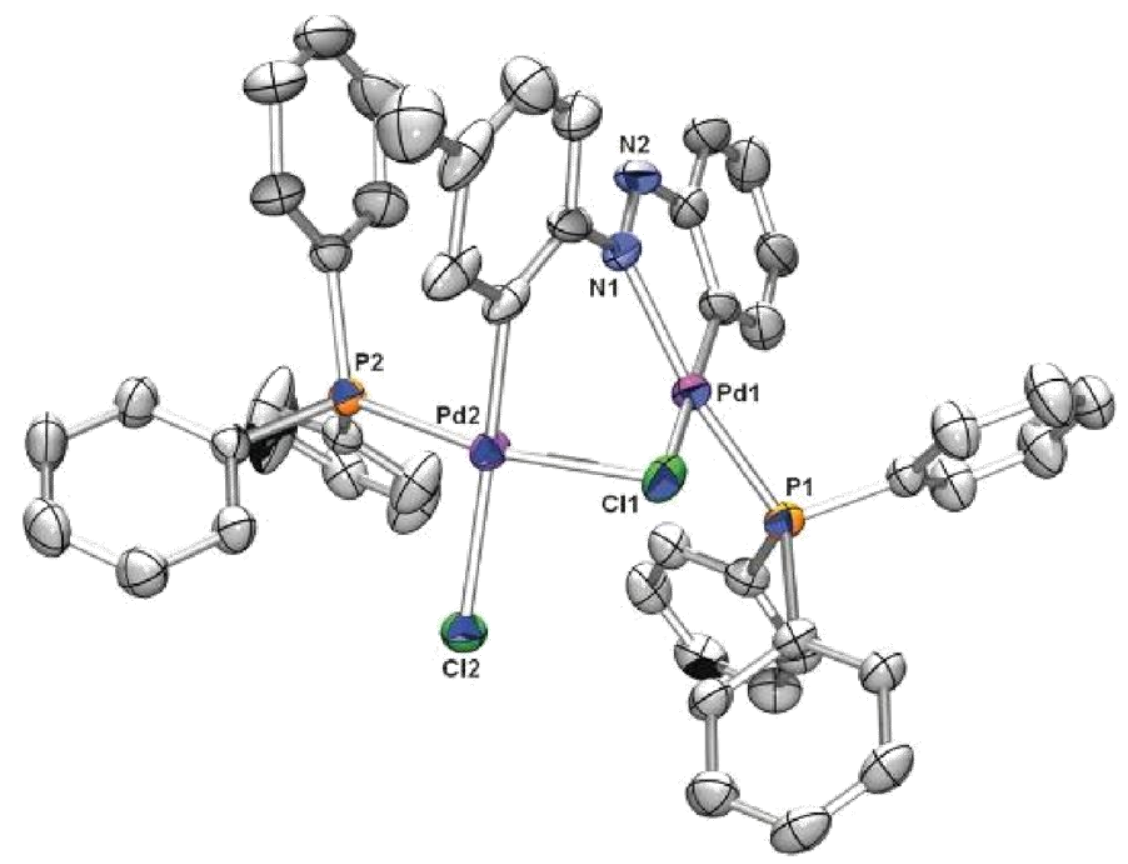

Fig 3 Molecular structure of the beta isomer of $2 \mathrm{a}$. Displacement ellipsoids are drawn at $30 \%$ probability level and hydrogen atoms are omitted for clarity

Table 1 Calculated energies for possible isomers of complexes $\mathbf{A}$ and $\mathbf{B}$ (in $\mathrm{kcal} \mathrm{mol}^{-1}$ ) relative to the most stable isomer of $\mathbf{A}$ in the gas phase

\begin{tabular}{|c|c|c|c|c|c|c|c|}
\hline \multirow[b]{3}{*}{ Complex $^{a}$} & \multicolumn{4}{|l|}{ A } & & \multicolumn{2}{|l|}{ B } \\
\hline & \multicolumn{2}{|l|}{ cis } & \multicolumn{2}{|l|}{ trans } & & \multirow[t]{2}{*}{ cis } & \multirow[t]{2}{*}{$\operatorname{tran} s$} \\
\hline & Alpha & Beta & Alpha & Beta & & & \\
\hline 1a & $0.0^{b}$ & & $7.6^{b}$ & & 1b & 2.5 & 12.7 \\
\hline $2 a$ & 0.0 & 0.1 & 7.6 & 8.3 & $2 b$ & 2.0 & 12.5 \\
\hline $3 a$ & 0.0 & 1.0 & 7.5 & 8.6 & $3 b$ & 1.7 & 11.5 \\
\hline $4 a$ & 0.0 & 2.2 & 8.1 & 8.4 & $4 b$ & 2.3 & 13.1 \\
\hline
\end{tabular}

crystal structure determinations, Fig. 1 and Fig. S2 (ESI $\dagger$ ). In all cases, except for $\mathbf{4 a}$, these pairs of PXRD patterns show a very good agreement. Thus, the solid-state reactions of 1-3 with $\mathrm{PPh}_{3}$ 
resulted in A complexes. The formation of $\mathbf{4 a}$ from precursor 4 was indicated by solid-state ${ }^{31} \mathrm{P}$ NMR spectrum of the ground product that contains two signals (31.34 and $39.89 \mathrm{ppm})$ since two atoms of phosphorus in all bridged complexes $\mathbf{1 a - 4 a}$ are not equivalent, Fig. 4b and Table S1 $($ ESI $\dagger$ ). In contrast to $\mathbf{A}$ complexes, two phosphorus atoms in $\mathbf{B}$ complex with azobenzene $\mathbf{1 b}$ are equivalent (Scheme 1), while in complexes with unsymmetrical substituted azobenzenes $\mathbf{2 b}$ 4b differences between them are too small to be visible in NMR spectra. Consequently, only one phosphorus signal should be present in spectra of $\mathbf{B}$ complex which was not the case here.
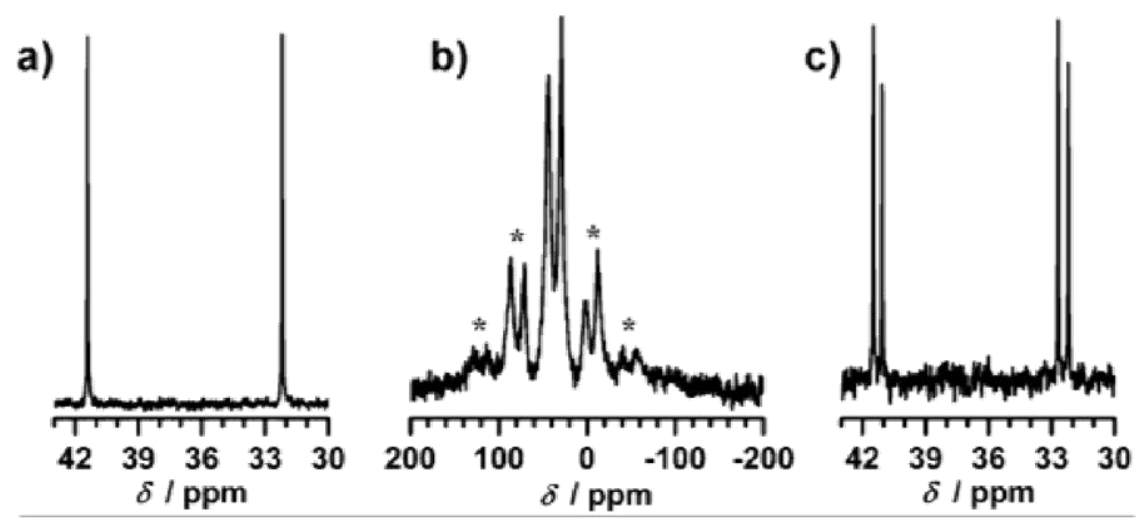

Fig $4^{31} \mathrm{P}$ NMR spectra of 1 a recorded in $\mathrm{CDCl}_{3}(\mathrm{a})$, 1a recorded in solid-state (b) and 2 a recorded in $\mathrm{CDCl}_{3}$ (c). The side bands are denoted by asterisks (*)

${ }^{31} \mathrm{P}$ NMR spectra recorded in $\mathrm{CDCl}_{3}$ revealed that only the structure of $\mathbf{2 a}$ in solution is not consistent with the observed solid-state structure. In contrast to 1a, 3a and $4 \mathbf{a}$ whose ${ }^{31} \mathrm{P}$ NMR spectra contain one set of two phosphorus signals (Fig. 4a), the spectrum of 2a contains double set of signals due to the simultaneous presence of alpha and beta isomers in the solution, Fig. 4c and Table S1 (ESI $\dagger$ ). Thus, dissolving 2a, isolated as a beta isomer, in $\mathrm{CDCl}_{3}$ results in equilibrium between alpha and beta isomers which is confirmed by variable-temperature ${ }^{1} \mathrm{H}$ NMR experiments, Fig. S6 (ESI †).

Quantum-chemical calculations have suggested that the products of the solid-state reactions are thermodynamically favorable since the isolated isomers 1a-4a are the most stable isomers in the gas phase, Table 1. The free energy difference between alpha and beta isomers of $\mathbf{2 a}$ is only $0.1 \mathrm{kcal}$ $\mathrm{mol}^{-1}$. Thus, the calculations support the formation of both isomers for $\mathbf{2 a}$.

In summary, we have presented the first examples of triphenylphosphine derivatives of dicyclopalladated azobenzenes obtained by solid-state synthesi s. This synthetic route produced bridged complexes and for the first time demonstrated that very complex molecular dynamics involving a series of structural transformations is also feasible in the solid state, Scheme 1 . The described results are important for understanding the structural transformations occurring during the mechanical processing of solid reactants and will have significant implication for the future design and synthesis of the new generation of coordination compounds

The authors thank the Ministry of Science, Educations and Sports of the Republic of 
Cinčić, D., Juribašić, M.,Babić, D.,Molćanov K., Šket, P., Plavec, J. and Čurić, M. (2011), “New insight into solid state molecular dynamics: mechanochemical synthesis of azobenzene/triphenylphosphine palladacycles", Chemical Communications, Vol. 47, No. 41, pp.11543-11545.

Croatia for financial support (grant nos.098-0982915-2950, 098-1191344-2943 and 1191193079-3069).

\section{Notes and references}

1 (a) M. Schlesinger, S. Shulze, M. Hietschold and M. Mehring, Microporous Mesoporous Mater., 2010, 132, 121; (b) D. Cinčić, T. Friščić and W. Jones, J. Am. Chem. Soc., 2008, 130 , 7524; (c) D. Braga, S. L. Giaffreda, F. Grepioni, A. Pettersen, L. Maini, M. Curzi and M. Polito, Dalton Trans., 2006, 1249; (d) G. Kaupp, CrystEngComm, 2006, 8, 794; (e) K. Tanaka and F. Toda, Chem. Rev., 2000, 100, 1025.

2 (a) P. . Beldon, . F bi n, R. S. Stein, A. Thirumurugan, A. K. Cheetham and T. Friščić, Angew. Chem., Int. Ed., 2010, 49, 9640; (b) A. Pichon and S. L. James, CrystEngComm, 2008, 10, 1839; (c) D. Braga and F. Grepioni, Angew. Chem., Int. Ed., 2004, 43, 4002.

3 (a) T.Friščić, in Metal-Organic Frameworks: Design and Application, ed. L. R. MacGillivray, John Wiley \& Sons, Inc., Hoboken, NJ, USA, 2010; (b) A. L. Garay, A. Pichon and S. L. James, Chem. Soc. Rev., 2007, 36, 846; (c) D. Braga, L. Maini, M. Polito, L. Mirolo and F. Grepioni, Chem.-Eur. J., 2003, 9, 4362.

4 (a) A. Stolle, T. Szuppa, S. E. S. Leonhardt and B. Ondruschka, Chem. Soc. Rev., 2011, 40, 2317; (b) D. Cinčić and B. Kaitner, CrystEngComm, 2011, 13, 4351; (c) G. A. Bowmaker, Effendy, J. V. Hanna, P. C. Healy, S. P. King, C. Pettinari, B. W. Skelton and A. H. White, Dalton Trans.,2011, 40, 7210; (d) R.Kuroda, J. Yoshida, A. Nakamura and S. Nishikiori, CrystEngComm, 2009, 11, 427;(e) J. Yoshida, S. Nishikiori and R. Kuroda, Chem.-Eur. J., 2008, 14, 10570;(f) C. J. Adams, H. M. Colquhoun, P. C. Crawford, M. Lusi and A. G. Orpen, Angew. Chem., Int. Ed., 2007, 46, 1124; (g) D. Braga, L. Maini, S. L. Giaffreda, F. Grepioni, M. R. Chierotti and R. Gobetto, Chem.-Eur. J., 2004, 10, 3261;(h) A. Orita, L. S. Jiang, T. Nakano, N. C. Ma and J. Otera, Chem.Commun., 2002, 1362; (i) V. P. Balema, J. W. Wiench, M. Pruski and V. K. Pecharsky, Chem. Commun., 2002, 1606; (j) J. F. Fernandez-Bertran, Pure Appl. Chem., 1999, 71, 581

5 (a) D. Babić, M.Curic, K. Molcanov, G. Ilc and J. Plavec, Inorg.Chem., 2008, 47, 10446; (b) M.Curic, D. Babic, A. Visnjevac and K. Molcanov, Inorg. Chem., 2005, 44, 5975

6 (a) M. Juribasic, M.Curic, K. Molcanov, D. Matkovic-Calogovic and D. Babic, Dalton Trans. 2010, 39, 8769; (b) S.-H. Li, C.-W. Yu and J.-G. Xu, Chem. Commun., 2005, 450; (c) J. Dupont, C. S. Consorti and J. Spencer, Chem. Rev, 2005, 105, 2527

7 (a) W. Yuan, T. Friscic, D. Apperley and S. L. James, Angew. Chem., Int. Ed., 2010, 49, 3916; (b) T. Friscic, A. V. Trask, W. Jones and W. D. S. Motherwell, Angew. Chem., Int. Ed., 2006, 45, 7546

8 N. Shan, F. Toda and W. Jones, Chem. Commun., 2002, 2372

9 (a) T. Friscic and W. Jones, Cryst. Growth Des., 2009, 9, 1621; (b) I. A. Tumanov, A. F. Achkasov, E. V. Boldyreva and V. V. Boldyrev, CrystEngComm, 2011, 13, 2213

10 G. A. Bowmaker, J. V. Hanna, B. W. Skelton and A. H. White, Chem. Commun., 2009, 2168 
Cinčić, D., Juribašić, M.,Babić, D.,Molćanov K., Šket, P., Plavec, J. and Čurić, M. (2011), “New insight into solid state molecular dynamics: mechanochemical synthesis of azobenzene/triphenylphosphine palladacycles", Chemical Communications, Vol. 47, No. 41, pp.11543-11545.

11 J. Vicente, A. Areas, D. Bautista and P. G. Jones, Organometallics, 1997, 16, 2127. 